\title{
Evaluation of arsenic field test kits as a learning exercise for engineering students in global water and sanitation class
}

\author{
Joshua Kearns \\ Assistant Professor \\ Global WaSH (Water-Sanitation-Hygiene) Faculty \\ Department of Civil, Construction, and Environmental \\ Engineering \\ North Carolina State University \\ jpkearns@ncsu.edu \\ Sarah Hartman \\ Technical Fellow, Caminos de Agua \\ hartman.sarahm@gmail.com \\ Miranda de Boskey \\ Chemist \\ Analytical Sciences Department \\ Research Triangle Institute \\ mdeboskey@rti.org
}

\author{
Aaron Krupp \\ Research \& Technology Development Coordinator, \\ Caminos de Agua \\ aaron@caminosdeagua.org
}

Kirstin Szogas

Undergraduate Student

Department of Civil, Construction, and Environmental

Engineering

North Carolina State University

kmszogas@,ncsu.edu

James M. Harrington

University Research Coordinator

Analytical Sciences Department

Research Triangle Institute

jharrington@rti.org

Abstract - Around 150 million people in more than 70 countries around the world are exposed to elevated levels of naturally occurring arsenic in groundwater used for drinking and cooking. Inexpensive arsenic field test kits are readily commercially available and have been promoted for classifying the safety of water sources. However, the accuracy and reliability of test kits has been called into question by some researchers. The purpose of this project was to provide decision support to a small nonprofit community development organization in central Mexico regarding the applicability of field test kits for assessing the safety of rural groundwater supplies. Test kit evaluation was conducted as an experiential learning exercise for undergraduate and graduate students in a University engineering course on Global Water and Sanitation. Recounting the scale and scope of the ongoing arsenic crisis in Bangladesh, as well as the sensational epidemic of "arsenical beer" in Manchester, England in 1900 that popularized the Gutzeit chemistry upon which test kits are based, spurred student interest and enthusiasm for the learning activities. Reviewing the contradictory and inconclusive literature from the recent two decades on the use of test kits provided a sobering case study for students to grapple with the difficulties and uncertainties inherent in conducting humanitarian science and engineering in the developing world. This study found generally poor performance of test kits, in particular for waters containing As in excess of $95 \mu \mathrm{g} / \mathrm{L}$. Additionally, the field kits tested could not be used to classify waters as "safe," i.e., below the WHO Guideline Value of $10 \mu \mathrm{g} / \mathrm{L}$ to $95 \%$ level of confidence. This study lends further caution to the use of test kits for identification of safe water sources. 
International Journal for Service Learning in Engineering, Humanitarian Engineering and Social Entrepreneurship Vol. 14, No. 1, pp. 32-46, Spring 2019

ISSN 1555-9033

Index terms - arsenic, Bangladesh, field test kits, groundwater, Mexico

\section{INTRODUCTION}

\section{The global arsenic public health crisis}

Exposure to elevated levels of arsenic (As) is associated with skin, bladder, and lung cancer, developmental effects in children, cardiovascular disease, and painful skin lesions. ${ }^{1}$ Naturally occurring arsenic in groundwater used for drinking and cooking is a global public health catastrophe affecting $\sim 150$ million people in more than 70 countries. ${ }^{2,3}$ The most intense expression of this crisis came to light in Bangladesh and West Bengal, India, in the late 1990's when it was discovered that around 33 million people were drinking water containing more than $50 \mu \mathrm{g} / \mathrm{L}$ (parts-per-billion) As. ${ }^{3}$ As of 2009 an estimated 22 million people were still drinking water that does not meet the Bangladesh standard of $50 \mu \mathrm{g} / \mathrm{L}$, and 5.6 million were exposed to As above $200 \mu \mathrm{g} / \mathrm{L} .{ }^{4}$ The World Health Organization (WHO) and many countries do not consider 50 $\mu \mathrm{g} / \mathrm{L}$ safe and recommend a Guideline Value of $10 \mu \mathrm{g} / \mathrm{L} .{ }^{1}$ At this level, around 50 million people in Bangladesh ( $40 \%$ of the total population) and about 12 million people in West Bengal are consuming dangerous quantities of arsenic. ${ }^{3}$

The origin of this crisis constitutes a tragic irony of unintended consequences. A policy promoted by UNICEF to reduce child mortality from enteric disease from the 1970s led to the drilling of tens of millions of tubewells to obtain microbiologically safe drinking water, since surface water quality was heavily impaired by fecal contamination. However, this unknowingly tapped aquifers containing high levels of geogenic As leading to what the World Health Organization (WHO) dubbed "the largest mass poisoning of a population in history." Extensive contamination was subsequently discovered in the river basins of Nepal, Myanmar, Cambodia, Vietnam, and Pakistan. ${ }^{3}$ For example, a recent study estimated that approximately 50 million to 60 million people use groundwater within the area at risk, with hot spots around megacities Lahore and Hyderabad. ${ }^{2}$

Regional hotspots of As contamination have also been identified in Central and South America and Mexico. ${ }^{3}$ One such hotspot is located in the Independence Watershed of central Mexico, in Guanajuato state. ${ }^{5}$ Caminos de Agua (hereafter, CdA; caminosdeagua.org) is a registered 501(c)(3) nonprofit in the U.S. as well as a Mexican Asociación Civil (A.C.) based in San Miguel de Allende. They work in partnership with local communities, research institutions, and other stakeholders to innovate and implement water solutions that create adequate access to safe, healthy drinking water supplies. Developing a reliable, accurate, cost-effective field testing protocol for As in groundwater is therefore critical to CdA's mission. Field test kits manufactured by $\mathrm{Hach}^{6}$ and ITS $^{7}$ are readily available online and have been promoted for inexpensive As quantitation under field conditions. However, the accuracy and reliability of field kits have been called into question. The Mexican drinking water standard for As is $25 \mu \mathrm{g} / \mathrm{L}$, whereas CdA's objective is to provide drinking water below the WHO Guideline Value of $10 \mu \mathrm{g} / \mathrm{L}$.

The objectives of this project were (1) determine the accuracy and precision of Hach and ITS field test kits for As quantitation under solution conditions relevant to groundwater in Independence watershed, Guanajuato, Mexico; (2) provide decision support to CdA regarding the 
applicability of field test kits for assessing the safety of community water supplies; and (3) utilize the process of accomplishing objectives (1) and (2) as an in-class learning exercise for $\sim 40$ students in the course "Water and Sanitation in Developing Countries" (catalog number CE 497/596 at North Carolina State University; hereafter, "WaSH class"). Technical learning outcomes included familiarization with the Hach and ITS kits and underlying chemistry; basic field-lab protocol and techniques including handling of hazardous reagents and wastes; simple experimental design and hypothesis testing; basic statistics, data analysis and reporting. Student interest and engagement with the course material was enhanced by recounting the fascinating backstory of the chemistry that underlies the test kits.

\section{History of the Gutzeit method}

As detection by field test kits is accomplished by the classic "Gutzeit method" first published in $1879 .{ }^{8}$ In a liquid sample, As is reduced to arsine gas $\left(\mathrm{AsH}_{3}\right)$ using acid and zinc granules or powder. The evolved arsine gas reacts with mercuric bromide bound to a paper strip to give a yellow color, which darkens with increasing As concentration. The early application of this method is an interesting instance of chemistry history worth expounding in the classroom as it can facilitate student engagement with the course material. Unless otherwise indicated, the following is summarized primarily from the article by Copping. ${ }^{9}$

The Gutzeit method gained rapid popularity in the early years of the twentieth century in response to a much smaller (compared with Bangladesh), though still sensational, crisis of arsenic poisoning that occurred in northwest England. ${ }^{10}$ 'Alcoholic peripheral neuritis' was a common condition among the poor of late-nineteenth Manchester and surroundings. The condition was characterized by fatigue and progressive paralysis, numbness and 'dropping' of the hands and feet, and muscle tenderness especially in leg muscles and soles of the feet. Because most of the sufferers of this condition were of low social class, the parochial British medical establishment regarded the condition simply as "a common penalty borne by those who indulge in alcoholic drinks." However, in the summer and fall of 1900 hospitals and clinics around Manchester saw a sharp increase in number of cases of "alcoholic neuritis." In some medical facilities one-quarter to one-half of patients presented with symptoms of the condition. The diagnosis of alcoholic neuritis was supported by the fact that all patients admitted to regular beer consumption. Apart from beer drinking, a large majority of suffers were low working-class laborers and paupers. Though patients admitted to beer drinking, most individuals reported their daily intake to be below the threshold thought to cause neuritis. However, due to social biases it was common for physicians to doubt patients' truthfulness in reporting beer consumption.

During the epidemic, physician Ernest Reynolds noted that many patients presented with symptoms of neuritis as well as skin rashes and discoloration. He also noticed that people who drank only liquor were unaffected by the condition despite consuming similar quantities of alcohol. Reynold's colleague Scottish physician William Gairdner also commented on "the great rarity of alcoholic neuritis amongst the whiskey-drinking poor of Glasgow - a group not usually noted for temperance of habit." This led Reynolds to suspect As contamination of the beer. Testing of local beers using the Gutzeit method began in mid-November of 1900 and the findings were reported in the British Medical Journal. ${ }^{11}$ By mid-December consensus was reached among medical practitioners that "arsenical beer" was responsible for the poisoning. The epidemic reached its 
apex in January of 1901 and decline thereafter, culminating with about 6,000 cases of illness and 70 deaths.

How did As get into beer? In order to offer a lower cost option to beer drinkers several Manchester brewers substituted a portion of high-quality malted barley with inexpensive refined sugar. The sugar was supplied by Bostock and Co. of Liverpool and was manufactured by hydrolysis of starch using sulfuric acid. The acid was derived from pyrites containing As, which transferred to the acid and sugar. Highly contaminated refined sugar in cheaper beers was thus responsible for the sharp increase in As poisoning. The background levels of alcoholic neuritis that existed for many years prior to the epidemic were explained by chronic exposure to smaller quantities of As associated with the malt. Barley malt was kiln dried by exposure to the hot vapors of a coal or coke fire - fuels which also contained traces of As that could be transferred to the malt.

A testing program using the Gutzeit chemistry was undertaken to identify and remove arsenical beer from the market. ${ }^{10}$ Subsequently, incidence of alcoholic neuritis dropped to rates comparable with rates in other British cities. Copping highlighted the impact that social class-based discrimination had on prolonging the crisis: "For many years prior to the epidemic, substantial numbers of beer drinkers had been systematically misdiagnosed as suffering from alcoholic neuritis when in reality they were being slowly poisoned by arsenic. The basis for this misdiagnosis was the willingness of the medical practitioners to disregard patient testimony in favor of prejudice about the honesty and reliability of the lower working class".

\section{Literature review of field test kits}

Surveying the peer-reviewed literature on field quantitation of As using test kits presents a valuable learning opportunity for students. The literature describing the accuracy and reliability of test kits is relatively contradictory and inconclusive. The summary below is not exhaustive but is sufficiently comprehensive to illustrate the discrepancies and uncertainties. From the studies available it cannot be concluded to an appropriate high level of confidence that test kits can be relied upon for determining drinking water safety from an As perspective. It's also not clear why the field kits have performed well in some circumstances and poorly in others. The As field test kit literature is thus a teachable case-study illustrating some of the difficulties and uncertainties encountered in conducting WaSH research and implementation in the developing world. The inherent challenge can motivate students' investigative desires to support water safety for communities and science-based consulting for development practitioners such as $\mathrm{CdA}$.

A 1999 study by Hussam and coworkers showed a poor correlation $\left(\mathrm{R}^{2} 0.2-0.5\right)$ between field test kit results and lab methods. ${ }^{12}$ This triggered further investigations into the use of kits for identifying safe versus unsafe wells in Bangladesh. The follow-up study by Rahman and coworkers found that $45 \%$ of 2,866 wells tested were misclassified by test kits as being below the $50 \mu \mathrm{g} / \mathrm{L}$ Bangladeshi standard. ${ }^{13}$ Test kits gave $68 \%$ false negative results and $35 \%$ false positive results compared to lab analysis. ${ }^{13}$ Spear and coworkers observed poor As quantitation from laboratory reagent water and groundwater spiked with $30 \mu \mathrm{g} / \mathrm{L}$ As for kits supplied by several manufacturers, including the Hach kit which evinced only $30-40 \%$ recovery. ${ }^{14}$ In contrast, Van Geen and coworkers found that the Hach field kit correctly determined the status of $88 \%$ of 799 wells in Bangladesh relative to the $50 \mu \mathrm{g} / \mathrm{L}$ standard. ${ }^{15}$ They also showed that the proportion of 
International Journal for Service Learning in Engineering, Humanitarian Engineering and Social Entrepreneurship Vol. 14, No. 1, pp. 32-46, Spring 2019

ISSN 1555-9033

incorrect results in the $50-100 \mu \mathrm{g} / \mathrm{L}$ range could be significantly reduced (from $79 \%$ to $2 \%$ ) by extending the reaction time from 20-40 minutes. ${ }^{15}$ Steinmaus and coworkers used ITS and Hach kits to test well water in Nevada. ${ }^{16}$ They found that kits were in the same As concentration bracket as determined by a lab method in $71 \%(\mathrm{n}=97$; ITS) and $62 \%(\mathrm{n}=84$; Hach) of samples and within one concentration bracket for $99 \%(\mathrm{n}=134$; ITS) and $97 \%(\mathrm{n}=132$; Hach) of samples, respectively. ${ }^{16}$ Relative to $50 \mu \mathrm{g} / \mathrm{L}$ As, false positive and negative rates were, respectively, $9.0 \%$ and $7.2 \%$ (ITS) and $3.0 \%$ and $8.7 \%$ (Hach). Relative to $10 \mu \mathrm{g} / \mathrm{L}$ As, false positive and negative rates were, respectively, $14.8 \%$ and $2.7 \%$ (ITS) and $7.4 \%$ and $4.6 \%$ (Hach). ${ }^{16}$ George and coworkers found that for 123 wells in Bangladesh, the ITS correctly determined the status of $89 \%$ of wells relative to the $10 \mu \mathrm{g} / \mathrm{L} \mathrm{WHO} \mathrm{Guideline} \mathrm{value} \mathrm{and} 92 \%$ of wells relative to the $50 \mu \mathrm{g} / \mathrm{L}$ local standard. ${ }^{17}$

Jakariya and coworkers tested 12,532 wells in Bangladesh using test kits manufactured by Merck and found overall that the kits classified wells correctly in $91 \%$ and $87 \%$ of samples with respect to the 50 and $10 \mu \mathrm{g} / \mathrm{L}$ local and WHO standards, respectively. ${ }^{18}$ However, around $85 \%$ of wells fell into $0-9.9 \mu \mathrm{g} / \mathrm{L}(\sim 28 \%), 100-499 \mu \mathrm{g} / \mathrm{L}(\sim 47 \%)$, and $\geq 500(10 \%)$ categories combined, whereas wells falling within $10-24,24-49$, or $50-99 \mu \mathrm{g} / \mathrm{L}$ As concentration brackets each accounted for only about $5 \%$ of samples. Relative to the $50 \mu \mathrm{g} / \mathrm{L}$ standard the percentage of wells correctly classified in the $50-99 \mu \mathrm{g} / \mathrm{L}$ category was $70 \%$. Relative to the $10 \mu \mathrm{g} / \mathrm{L}$ standard the percentage of wells correctly classified in the $10-24 \mu \mathrm{g} / \mathrm{L}$ category was $47 \% .{ }^{18}$ Thus the reported high overall rates of correct classification $(\sim 90 \%)$ reflect bias due to the bimodal distribution of As in wells of the sample set (i.e., a large percentage of wells are either very high or very low). For wells with As concentrations nearer the critical values of 10 and $50 \mu \mathrm{g} / \mathrm{L}$ the kits performed rather poorly.

Environmental Technology Verification (ETV) reports for the ITS Quick II and ITS Quick Low Range II test kits were prepared by Batelle under cooperative agreement with US EPA. ${ }^{19,20}$ These kits are predecessors to the Quick Arsenic Econo II kit used in the present study, for which an ETV is currently not available. Data have been extracted from the ETV reports and summarized in Tables 1A and 1B in the Appendix. The ETV studies found average false positive rates of $0 \%$ and false negative rates of $22 \%$ and $48 \%$ for the Quick II and Low-Range II kits, respectively. The average As recoveries ranged from $48 \%$ to $75 \%$, showed significant variability (i.e., large standard deviations). On average, recoveries were lower and had larger standard deviations in As-spiked environmental waters compared with spiked laboratory ("DI") water. The accuracy of the kits showed significant negative bias, underreporting As concentrations by $33 \%$ on average. The negative bias was stronger for environmental waters than DI water $-56 \%$ and $58 \%$ versus $8 \%$ and $12 \%$ for the Quick II and Low-Range II kits, respectively. Overall test kit accuracy assessed by agreement within $+/$ - one color block As concentration bracket averaged $70 \%$ and $42 \%$ for the Quick II and Low-Range II kits, respectively. Accuracy assessed by agreement within $+/$ - one color block was lower for environmental waters than DI water. As concentration bracket Interestingly, in many cases testing accuracy was higher and incidence of bias lower for the "nontechnical" versus the "technical" kit operator. In summary, the kits as tested in the ETV program evince significant variability between users, consistent and substantial underestimation of As concentrations, and stronger negative bias in representative environmental waters compared with laboratory reagent DI water. 
Researchers have identified several factors that can lead to inaccurate As measurements using field test kits. For example, As in sample water is reduced using acid and zinc. However, zinc ores often contain traces of As which can transfer to the $\mathrm{Zn}$ reagent and this was shown to affect test kit reliability in Bangladesh. ${ }^{21}$ Kinniburg and Kosmus ${ }^{21}$ also specify that $\mathrm{Zn}$ granules promote more favorable reaction kinetics compared with $\mathrm{Zn}$ powder; however most kits such as those tested here utilize Zn powder. Researchers have also noted the relatively low sensitivity of the human eye to variations of yellow color, especially under the range of different lighting conditions that exist in the field. ${ }^{13,21}$ Moreover, the reaction that produces yellow stain on the test strip is timesensitive. Significant variability arises from when the strip is read and ambient conditions such as temperature and humidity that can affect reaction kinetics (Kinniburgh and Kosmus 2002). Spear and coworkers found significant performance variability between two test kits supplied by the same manufacturer (ITS). ${ }^{14}$ In this case, the discrepancy was attributed to a flaw in product packaging that resulted in a reaction between the mercuric bromide paper strips and the aluminum foil lining of the pouch in which they are shipped and stored. Strips from faulty packages showed $\mathrm{As}^{\mathrm{III}}$ recoveries of $64 \%, \mathrm{As}^{\mathrm{V}}$ recoveries of $7 \%$, and $\mathrm{As}^{\mathrm{III}}+\mathrm{As}^{\mathrm{V}}$ recoveries from mixtures of $34 \%$, compared with $94 \%, 96 \%$, and $100 \%$, respectively, for strips supplied in redesigned packaging.

In summary, from surveying the available literature it is difficult to ascertain a high level of confidence in the accuracy and reliability of As field test kits based on the Gutzeit method.

\section{METHODS}

\section{Sample collection and preservation}

Distilled water (DI) was purchased from a local mechanic shop in San Miguel de Allende, Mexico. San Miguel municipal piped water (TAP) was collected from a tap in the CdA laboratory. Well water was collected during summer 2017 (WELL1) and during spring 2018 (WELL2) from the rural village of Ex Hacienda de Jesus in Guanajuato state. As from a concentrated stock solution was spiked into DI, TAP, and WELL1 waters at levels of $0,10,20,50$, and $80 \mu \mathrm{g} / \mathrm{L}$ above the level of background (native) As. Samples were acidified to $\mathrm{pH} \leq 2$ with $\mathrm{HCl}$ to prevent formation of iron oxyhydroxide precipitates onto which As can sorb, inhibit biological activity, and maintain As in dissolved form. ${ }^{22}$ Water samples were sub-sampled for analysis by CdA staff using an ITS test kit, and were transported in checked luggage to NC State University where they were stored refrigerated and in the dark until analysis by WaSH class students. Code names for samples were used so that students and ICP-MS analysts were blinded during quantitation.

Analysis by ICP-MS

ICP-MS analyses were performed at Research Triangle Institute (RTI) International. Samples were prepared in a Class 100 clean hood to prevent contamination and were diluted with a nitric acid solution to a $2 \%$ nitric acid final matrix composition. After preparation, the samples were analyzed for trace minerals using the Thermo (Bremen, Germany) X-Series II ICP-MS equipped with a concentric glass nebulizer and peltier-cooled glass impact bead spray chamber. The instrument was operated in collision cell mode and tuned daily to control interferences arising from $\mathrm{ArCl}$. Calibration standards for ICP-MS analysis were prepared by dilution of NIST-traceable 10 and 
$1,000 \mathrm{mg} / \mathrm{L}$ As standard in a nitric acid solution. Continuing calibration check samples were analyzed at most after every ten samples and consisted of a blank measurement to monitor carryover and a calibration standard to assess instrument performance. The limit of quantification (LOQ) was taken as the lowest concentration calibration standard, $0.50 \mu \mathrm{g} / \mathrm{L}$ and the limit of detection was calculated as a function of the standard deviation of the measured signal of method blank samples, $0.035 \mu \mathrm{g} / \mathrm{L}$. For the calibration, standards were accepted as passing if their backcalculated concentration was found to be within $\pm 15 \%$ of the nominal concentration ( $\pm 25 \%$ of the nominal concentration for the lowest concentration standard). Quality control checks were accepted as passing if the determined concentration for all elements was found to be within $\pm 15 \%$ of the nominal concentration. Several samples were prepared in duplicate to monitor reproducibility, and several samples were prepared in duplicate with addition of $5 \mu \mathrm{g} / \mathrm{L}$ of As. Recovery for spiked samples generally fell between $96 \%$ and $112 \%$ and calculated percent difference for duplicate samples was less than $1.2 \%$ for all samples. Method blank samples were analyzed prior to study samples and produced a background concentration of $0.011 \mu \mathrm{g} / \mathrm{L}$ As.

\section{Analysis by Hach and ITS field kits}

The spring $2018 \mathrm{WaSH}$ class consisted of 30 senior undergraduate and 8 graduate students in civil, environmental, and construction engineering programs. Students were divided into eight groups of four to five students each, given one coded water sample, and instructed to perform one analysis with the Hach kit and two analyses with the ITS kits. Replicate analyses were performed with the ITS kit since those are what CdA primarily uses and therefore warrant more attention. Students followed the directions given in the kit product information sheets under light supervision by the course instructor. One undergraduate student from the course was paid hourly to work after class to complete the testing so that each sample was analyzed once by the Hach kit and twice by the ITS kit. For a second round of testing, water samples containing 5-83 $\mu \mathrm{g} / \mathrm{L}$ As were made by diluting WELL1 and WELL2 waters with different ratios of laboratory DI water, and by combining WELL1 and WELL2 waters in different ratios. The rationale was that if species are present in well water that suppress or amplify As response by the test kit, these species would also be diluted by DI water but would be present in approximately similar amounts in blended well water. Blended and diluted well water samples were made and coded by the instructor for blinding, then analyzed in triplicate using the ITS kit by the same WaSH class undergraduate student.

Instructions supplied with the ITS kit indicate that water samples should be analyzed immediately and without prior addition of preservative(s). However, this is not practical in many field circumstances. Preservation of many samples collected over days and stored up to one week for analysis in batches is necessary for the workflow of $\mathrm{CdA}$ as well as other field practitioners. Therefore, dilutions of WELL1 water using local distilled water were prepared by CdA tech staff and analyzed with and without preservation by addition of $\mathrm{HCl}$ to $\mathrm{pH} \leq 2$ to investigate the effect of acidification on ITS test kit response. 


\section{RESULTS AND DisCuSSION}

\section{ICP-MS analysis of field water samples}

Figure 1 displays As concentrations in DI, TAP, and WELL waters spiked with 0, 10, 20, 50, and $80 \mu \mathrm{g} / \mathrm{L}$ As quantified by ICP-MS (herein denoted "accurate" As concentrations). ICP-MS is a suitable method for aqueous As quantitation as defined in Standard Methods for the Examination of Water and Wastewater ${ }^{23}$ For each spiked water series slopes were $1.0 \pm 0.1$ and $\mathrm{R}^{2}$ values $>0.98$. Intercept values, which correspond to no As spike, indicate that As in DI was below detection level, $11.7 \mu \mathrm{g} / \mathrm{L}$ in TAP water, and 94.7 and $46.3 \mu \mathrm{g} / \mathrm{L}$ in WELL1 and WELL2 wasters, respectively. Furthermore, matrix interference with As quantitation by ICP-MS was not apparent for the DI, TAP, and WELL waters tested (Figure 1).

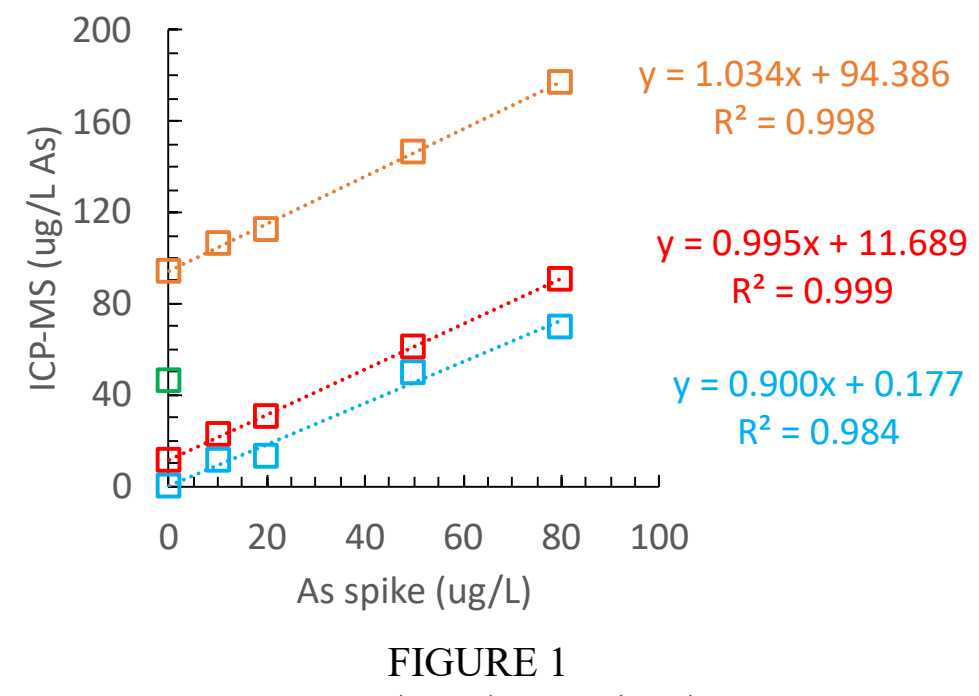

ACCURATE AS CONCENTRATIONS IN DI (BLUE), TAP (RED), AND WELL WATERS (WELL1 ORANGE, WELL2 GREEN) SPIKED WITH 0, 10, 20, 50, AND $80 \mu \mathrm{G} / \mathrm{L}$ AS QUANTIFIED BY ICP-MS.

\section{Performance of Hach and ITS field test kits}

Figure 2 displays As concentrations in DI, TAP, and WELL waters measured by ITS and Hach kits (y-axes) compared with accurate quantitation by ICP-MS (x-axes). In nearly all water samples, test kits significantly underestimated As concentrations as quantified by ICP-MS. The ITS kit showed a weak linear response with increasing As concentration (Figures 2a-c). The Hach kit showed poor correspondence between As concentration and test kit results (Figure 2d). Significant differences were not observed between ITS test kit results when analyses were performed by CdA tech staff (data indicated by triangles in Figures 2a-c) or WaSH class student(s) (data indicated by circles in Figures 2a-c). Within the precision of the data it is not possible to resolve an effect of the background water matrix (i.e., DI versus TAP versus WELL waters). The ITS kit showed poor correspondence for As concentrations exceeding $\sim 95 \mu \mathrm{g} / \mathrm{L}$ (Figure $2 \mathrm{~b}$ ). This result is unsurprising 
given the low optimal detection ranges reported for ITS kits in the ETV studies $(<10-15 \mu \mathrm{g} / \mathrm{L}$, Tables 1a-b). ${ }^{19,20}$
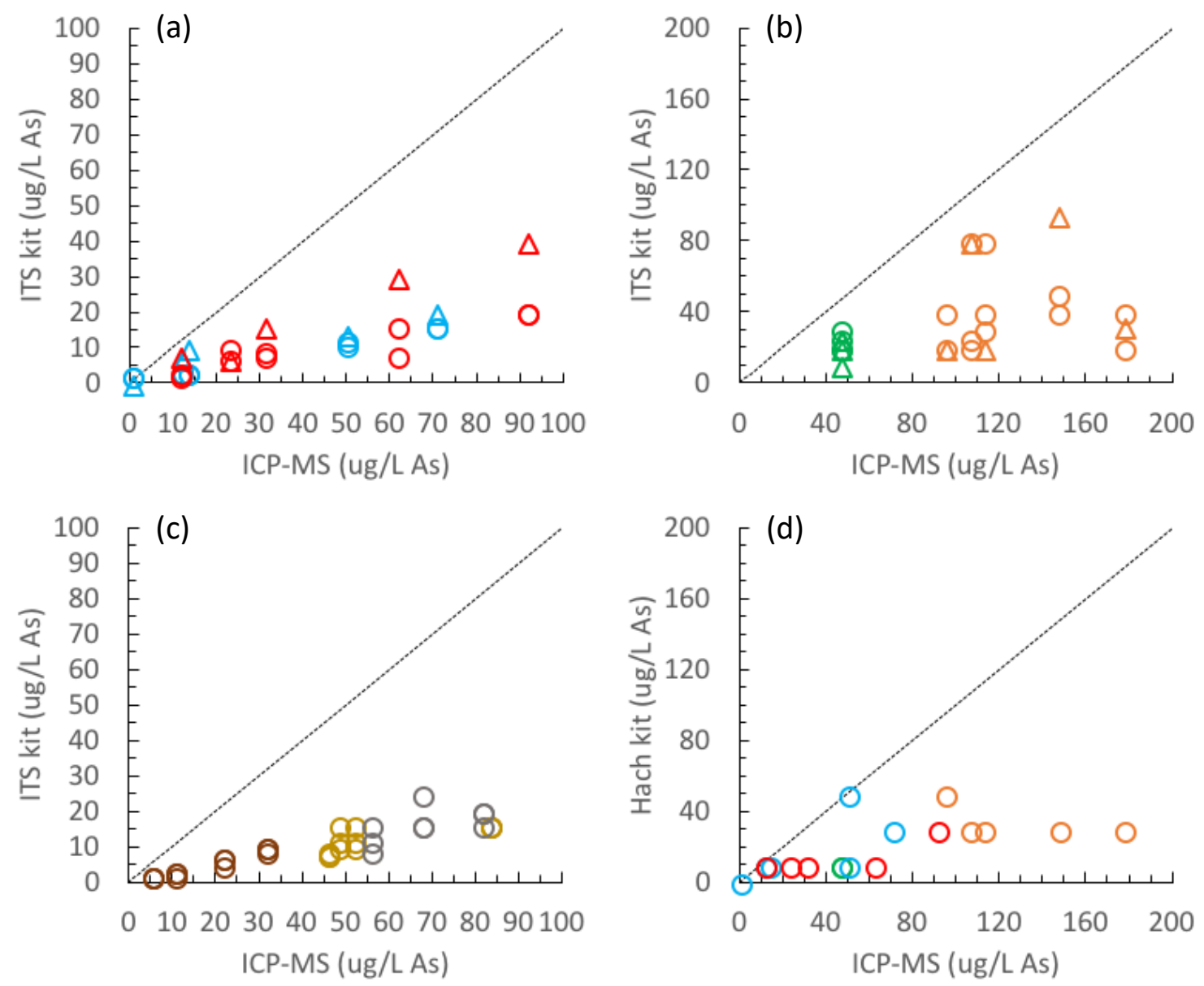

FIGURE 2

AS CONCENTRATIONS IN DI (BLUE), TAP (RED) [PANEL A], AND WELL (WELL1 ORANGE, WELL2 GREEN) WATERS [PANEL B], WELL WATER BLENDS (GRAY) AND DILUTIONS (BROWN, YELLOW) [PANEL C] MEASURED BY ITS [PANELS A-C] AND HACH [PANEL D] KITS COMPARED WITH ACCURATE QUANTITATION BY ICP-MS. CIRCLES INDICATED QUANTITATION PERFORMED BY NCSU WASH CLASS STUDENT(S), AND TRIANGLES INDICATE QUANTITATION PERFORMED BY CDA TECH STAFF. THE DIAGONAL DOTTED LINES INDICATE 1:1 CORRESPONDENCE BETWEEN TEST KIT RESULTS AND ICP-MS RESULTS.

\section{Effect of acid stabilization of water samples}

Figure 3 shows As quantified by CdA tech staff using the ITS kit for WELL2 water diluted with different ratios of local distilled water. As concentrations given on the X-axis are designated "nominal" because dilutions of WELL2 water were not analyzed by ICP-MS. Within the precision of the data a significant effect of sample preservation by acidification was not observed. 


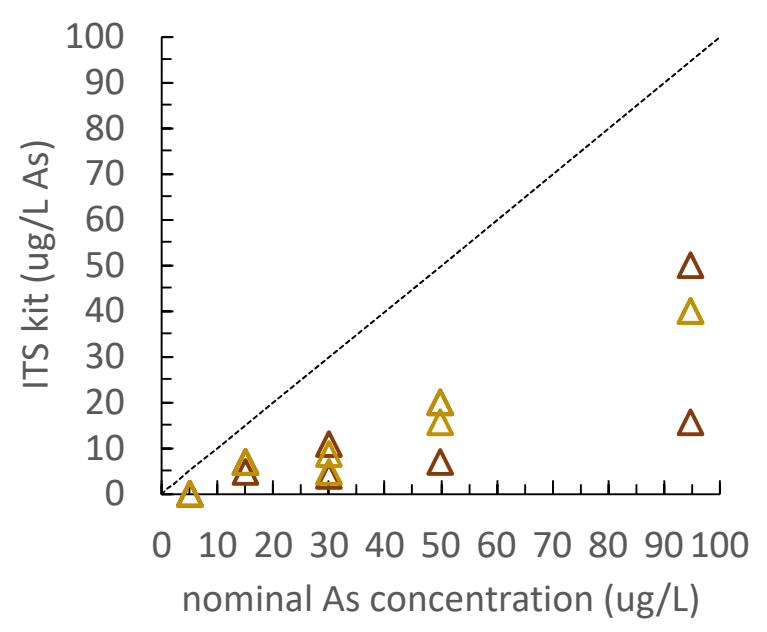

FIGURE 3.

AS QUANTIFIED BY CDA TECH STAFF USING THE ITS KIT FOR WELL2 WATER DILUTED WITH DIFFERENT RATIOS OF LOCAL DISTILLED WATER. AS CONCENTRATIONS ON THE X-AXIS ARE DESIGNATED “NOMINAL" BECAUSE DILUTIONS OF WELL2 WATER WERE NOT ANALYZED BY ICPMS BUT WERE INFERRED. SAMPLES ACIDIFIED BY HCL TO PH $\leq 2$ PRIOR TO ANALYSIS ARE SHOWN IN YELLOW. SAMPLES ANALYZED WITHOUT ACIDIFICATION ARE SHOWN IN BROWN. THE DIAGONAL DOTTED LINE INDICATES 1:1 CORRESPONDENCE BETWEEN TEST KIT AND ICP-MS RESULTS.

\section{Recommendations for use of (ITS) test kits}

The primary objective of this project was to provide decision support to CdA regarding the accuracy, reliability, and potential for utilization of test kits for classifying the safety of community water supplies. To this end the NCSU WaSH class developed a conservative approach using basic statistics and the dataset made available through this exercise. Significant distinctions in ITS test kit quantitation of As in different water matrices and by different operators were not observed within the precision of the method. Moreover, kits are available for online purchase by trained and untrained operators alike for use in a wide variety of field settings. Accordingly, all ITS kit data for As $<95 \mu \mathrm{g} / \mathrm{L}$ irrespective of water type or operator were fitted with a linear regression trendline as shown in Figure 4. The slope factor of 0.24 indicates that, on average, the ITS kit underestimated As concentration by approximately a factor of four. The $\mathrm{R}^{2}$ value of 0.59 reflects substantial variance in the data. The "Data Analysis" function in MS Excel was used to perform the regression analysis and calculate upper and lower $95 \%$ confidence intervals. The linear least squares fit and $95 \%$ confidence intervals were used to calculate calibrated mean, lower, and upper bounds for the test kit color chart brackets (Figure 5). Using this approach, a water sample giving an ITS color chart reading of $12 \mu \mathrm{g} / \mathrm{L}$, for example, could be reported as corresponding to an As concentration of $26-63 \mu \mathrm{g} / \mathrm{L}$ to a $95 \%$ level of confidence. Note that to a $95 \%$ confidence level the ITS kit cannot be used to classify water as "safe" according to the WHO Guideline Value of $10 \mu \mathrm{g} / \mathrm{L} \mathrm{As}$, since the calibration upper bound exceeds this value (i.e., the $95 \%$ confidence range extends to 11.6 $\mu \mathrm{g} / \mathrm{L})$. Water samples falling into the lowest two brackets on the ITS color chart (" $<2$ " and " 3 " $\mu \mathrm{g} / \mathrm{L}$ ) could be classified as below the Mexican standard of $25 \mu \mathrm{g} / \mathrm{L}$ to a $95 \%$ level of confidence. 
International Journal for Service Learning in Engineering, Humanitarian Engineering and Social Entrepreneurship Vol. 14, No. 1, pp. 32-46, Spring 2019

ISSN 1555-9033

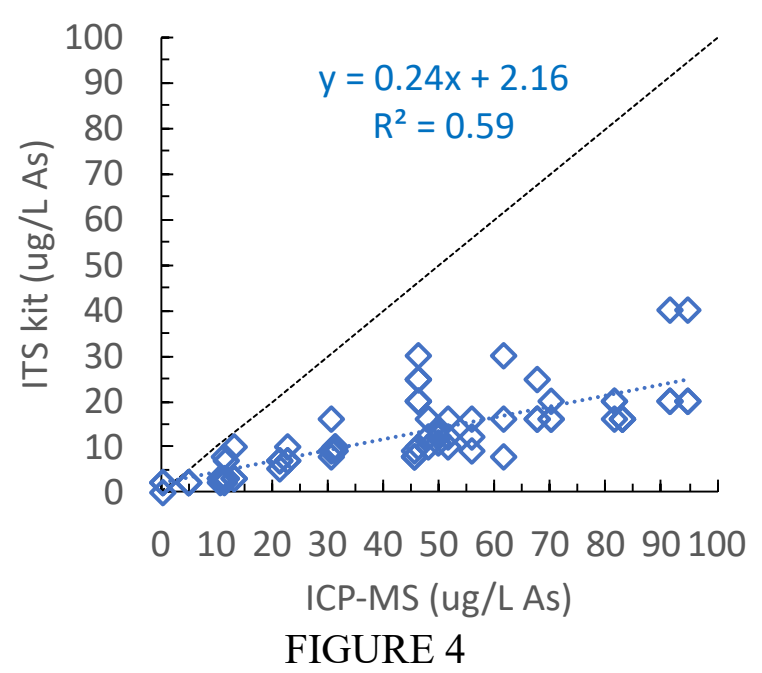

ITS KIT DATA FOR ALL WATER SAMPLES WITH AS $<95 \mu \mathrm{G} / \mathrm{L}$ ANALYZED BY CDA TECH STAFF AND NCSU WASH CLASS STUDENT(S). THE DIAGONAL DOTTED LINE INDICATES 1:1 CORRESPONDENCE BETWEEN TEST KIT RESULTS AND ICP-MS RESULTS.

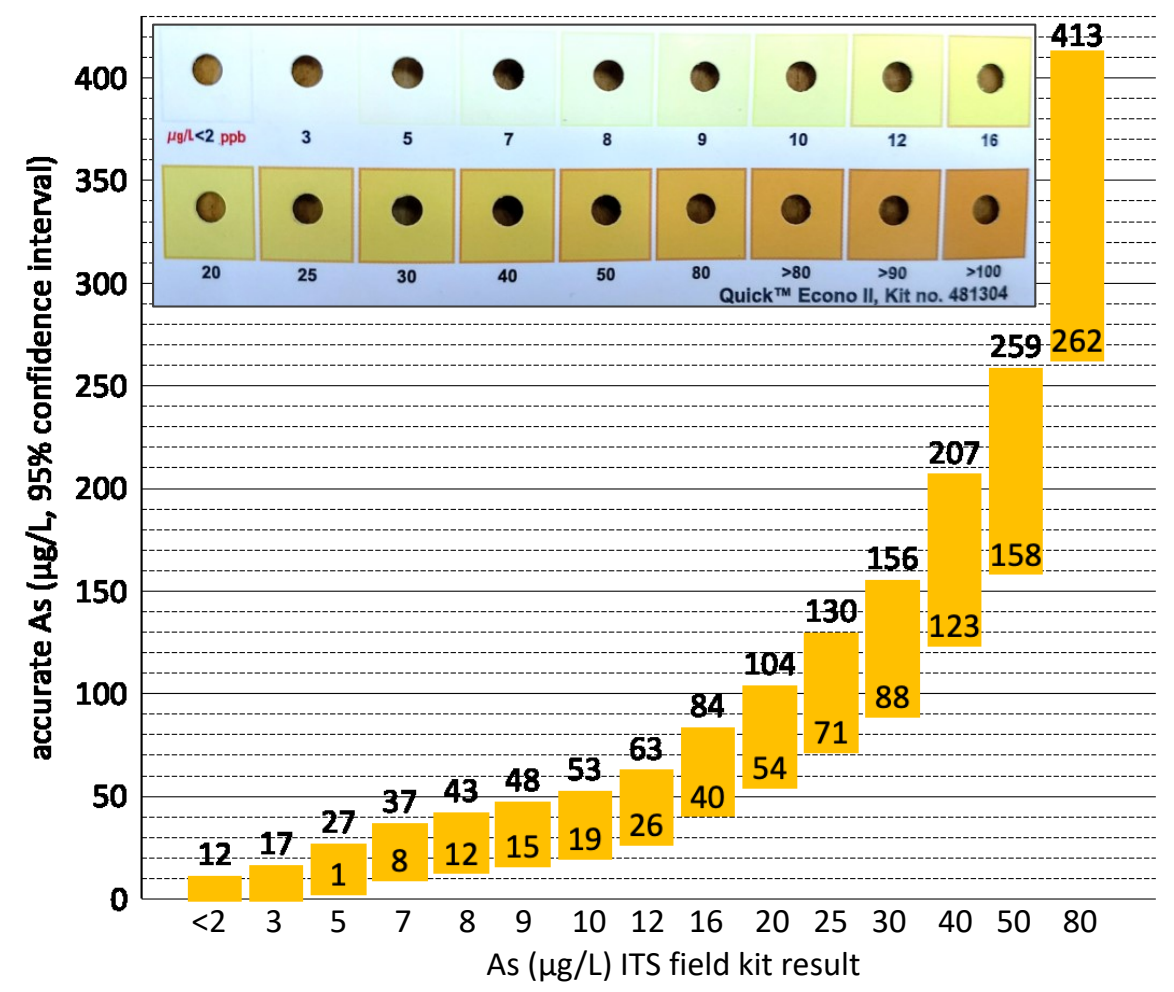

FIGURE 5

CALIBRATION OF ITS COLOR CHART READINGS USING ICP-MS DATA. NUMBERS ON BARS REPRESENT UPPER AND LOWER BOUNDS OF A 95\% CONFIDENCE INTERVAL. INSET SHOWS THE COLOR CHART SUPPLIED WITH THE TEST KITS FOR VISUALLY ESTIMATING AS CONCENTRATION BY COMPARISON WITH TEST STRIPS AFTER REACTION WITH WATER SAMPLES. FOR THE CATEGORY “ $<2$ " A VALUE OF $1.99 \mu \mathrm{G} / \mathrm{L}$ WAS USED FOR CALCULATIONS. 
International Journal for Service Learning in Engineering, Humanitarian Engineering and Social Entrepreneurship Vol. 14, No. 1, pp. 32-46, Spring 2019

ISSN 1555-9033

\section{CONCLUSION}

This study showed poor correlation between As concentration and test kit response for the Hach kit over the range tested (0-177 $\mu \mathrm{g} / \mathrm{L}$ As), and for the ITS kit when As exceeded $\sim 95 \mu \mathrm{g} / \mathrm{L}$. Below $95 \mu \mathrm{g} / \mathrm{L}$ the ITS kit showed a weak linear response with increasing As concentration, but was a factor of three-to-four low compared with As quantified by ICP-MS. Within the precision of the method, no effect of background water chemistry or test kit operator were observed. The field kits tested could not be used to classify waters as "safe," i.e., below the WHO Guideline Value of 10 $\mu \mathrm{g} / \mathrm{L}$ to $95 \%$ level of confidence. The ITS kit could be used to classify waters as below the Mexican drinking water As standard of $25 \mu \mathrm{g} / \mathrm{L}$ with a $95 \%$ level of confidence.

The literature describing the accuracy and reliability of As field test kits is relatively contradictory and inconclusive. This study lends further caution to the use of test kits for identification of safe water sources. Involving students in this project fostered a lot of discussion regarding the challenges and uncertainties associated with humanitarian science and engineering in low resource settings. Providing contextual background for As field testing through readings and discussion of the ongoing crisis in Bangladesh and the sensational "arsenical beer" epidemic among the working poor of Manchester, England in 1900 spurred interest and engagement of students with the course material and hands-on activities.

\section{ACKNOWLEDGMENT}

The authors would like to acknowledge RTI International for financial support of some of the laboratory analyses described in this paper. This project was inspired by a discovery made by Caminos de Agua technician Martijn Eikelboom of inconsistencies in As data collected by field kits versus a commercial laboratory. Eikelboom and fellow technical team member Simona Dossi conducted the preliminary investigation outlining the extent of the problem ${ }^{24}$ which served as the basis for this teaching exercise.

\section{REFERENCES}

${ }^{1}$ WHO. 2011. Guidelines for Drinking Water Quality: Fourth Edition Incorporating the First Addendum.

2 Podgorski, Joel E., Syed Ali Musstjab Akber Shah Eqani, Tasawar Khanam, Rizwan Ullah, Heqing Shen, and Michael Berg. 2017. "Extensive arsenic contamination in high-pH unconfined aquifers in the Indus Valley." Science Advances 3 (8). doi: 10.1126/sciadv.1700935.

${ }^{3}$ Ravenscroft, P., H. Brammer, and K. Richards. 2009. Arsenic Pollution: A Global Synthesis. West Sussex, PO19 8SQ, UK: Wiley-Blackwell.

${ }^{4}$ UNICEF. 2009. Bangladesh National Drinking Water Quality Survey of 2009. Bangladesh Bureau of Statistics. 2009.

5 Armienta, M. A., and N. Segovia. 2008. "Arsenic and fluoride in the groundwater of Mexico." Environmental Geochemistry and Health 30 (4):345-353. doi: 10.1007/s10653-008-9167-8.

${ }^{6}$ Hach. Arsenic Low Range Test Kit, Product \#:2800000. https://www.hach.com/arsenic-low-range-test$\mathrm{kit} /$ product? $\mathrm{id}=7640217303 \&$ callback $=$ pf (accessed 070718).

${ }^{7}$ ITS. Industrial Test Systems Econo-Quick II 481304 Arsenic for Water Quality Testing. https://www.amazon.com/gp/product/B00DIJBG1W/ref=oh_aui_search_detailpage?ie=UTF8\&psc=1 (accessed 071818). 
International Journal for Service Learning in Engineering, Humanitarian Engineering and Social Entrepreneurship Vol. 14, No. 1, pp. 32-46, Spring 2019

ISSN 1555-9033

${ }^{8}$ Gutzeit, H. 1879. Pharm. Zeitung 24.

${ }^{9}$ Copping, M. 2009. "Death in the beer glass: the Manchester arsenic-in-beer epidemic of 1900-1 and the long-term poisoning of beer." Journal of the Brewery History Society (132):31-57.

${ }^{10}$ Sanger, C. R., and O. F. Black. 1907. "The quantitative determination of arsenic by the Gutzeit method." Proceedings of the American Academy of Arts and Sciences 43 (1/12):297-324. doi: 10.2307/20022326.

${ }^{11}$ Reynolds, E. S. 1900. "An epidemic of peripheral neuritis amongst beer drinkers in Manchester and District." British Medical Journal 1900:1492-1493.

${ }^{12}$ Hussam, A., M. Alauddin, A. H. Khan, S. B. Rasul, and A. K. M. Munir. 1999. "Evaluation of arsine generation in arsenic field kit." Environmental Science \& Technology 33 (20):3686-3688. doi: DOI 10.1021/es9901462.

${ }^{13}$ Rahman, Mohammad Mahmudur, Debapriyo Mukherjee, Mrinal Kumar Sengupta, Uttam Kumar Chowdhury, Dilip Lodh, Chitta Ranjan Chanda, Shibtosh Roy, Md Selim, Quazi Quamruzzaman, Abul Hasnat Milton, S. M. Shahidullah, Md Tofizur Rahman, and Dipankar Chakraborti. 2002. "Effectiveness and Reliability of Arsenic Field Testing Kits: Are the Million Dollar Screening Projects Effective or Not?" Environmental Science \& Technology 36 (24):5385-5394. doi: 10.1021/es020591o.

${ }^{14}$ Spear, J. M., Y. Zhou, C. A. Cole, and Y. F. F. Xie. 2006. "Evaluation of arsenic field test kits for drinking water analysis." Journal American Water Works Association 98 (12):97-105.

${ }^{15}$ Van Geen, A., Z. Cheng, A. A. Seddique, M. A. Hoque, A. Gelman, J. H. Graziano, H. Ahsan, F. Parvez, and K. M. Ahmed. 2005. "Reliability of a commercial kit to test groundwater for arsenic in Bangladesh." Environmental Science \& Technology 39 (1):299-303. doi: 10.1021/es0491073.

${ }^{16}$ Steinmaus, C. M., C. M. George, D. A. Kalman, and A. H. Smith. 2006. "Evaluation of two new arsenic field test kits capable of detecting arsenic water concentrations close to $10 \mathrm{mu}$ g/L." Environmental Science \& Technology 40 (10):3362-3366. doi: 10.1021/es060015i.

${ }^{17}$ George, C. M., Y. Zheng, J. H. Graziano, S. Bin Rasul, Z. Hossain, J. L. Mey, and A. van Geen. 2012. "Evaluation of an Arsenic Test Kit for Rapid Well Screening in Bangladesh." Environmental Science \& Technology 46 (20):11213-11219. doi: 10.1021/es300253p.

${ }^{18}$ Jakariya, M., M. Vahter, M. Rahman, M. A. Wahed, S. K. Hore, P. Bhattacharya, G. Jacks, and L. A. Persson. 2007. "Screening of arsenic in tubewell water with field test kits: Evaluation of the method from public health perspective." Science of the Total Environment 379 (2-3):167-175. doi: 10.1016/j.scitotenv.2006.11.053.

${ }^{19}$ Kaufman, T., P. White, A. Dindal, Z. Willenberg, and K. Riggs. 2003a. Environmental Technology Verification Report, Industrial Test Systems, Inc. QuickTM II Test Kit. Columbus, OH: Batelle, USEPA.

${ }^{20}$ Kaufman, T., P. White, A. Dindal, Z. Willenberg, and K. Riggs. 2003b. Environmental Technology Verification Report, Industrial Test Systems, Inc. QuickTM Low Range II Test Kit. Columbus OH: Batelle, USEPA.

${ }^{21}$ Kinniburgh, D. G., and W. Kosmus. 2002. "Arsenic contamination in groundwater: some analytical considerations." Talanta 58 (1):165-180. doi: Pii S0039-9140(02)00265-5. Doi 10.1016/S0039-9140(02)00265-5.

${ }^{22}$ Kumar, A. Ramesh, and P. Riyazuddin. 2010. "Preservation of inorganic arsenic species in environmental water samples for reliable speciation analysis." TrAC Trends in Analytical Chemistry 29 (10):1212-1223. doi: https://doi.org/10.1016/j.trac.2010.07.009.

${ }^{23}$ American Public Health Association, American Water Works Association, and Water Environment Federation. 2018. Standard methods for the examination of water and wastewater. New York: The Association.

${ }^{24}$ Dossi, S. 2017. Low-cost arsenic testing in natural groundwater: reagent and method validation An investigation into the accuracy and reliability of commercial arsenic field test kits and appropriate validation methods Caminos de Agua. https://www.dropbox.com/s/vxmtua8fkfova6p/ArsenicTestValidation_v3.pdf?dl=0.

\section{APPENDIX}


International Journal for Service Learning in Engineering,

Humanitarian Engineering and Social Entrepreneurship

Vol. 14, No. 1, pp. 32-46, Spring 2019

ISSN 1555-9033

\section{TABLE $1 \mathrm{~A}$}

SUMMARY OF ENVIRONMENTAL TECHNOLOGY VERIFICATION (ETV) DATA FOR THE ITS QUICK ARSENIC II TEST KIT (KAUFMAN ET AL. 2003A). QCS = QUALITY CONTROL STANDARD, LABORATORY REAGENT WATER SPIKED WITH $10 \mu \mathrm{G} / \mathrm{L}$ AS. LFM = LABORATORY FORTIFIED MATRIX, SAMPLES OF ENVIRONMENTAL WATER SPIKED WITH $10 \mu \mathrm{G} / \mathrm{L}$ AS ABOVE NATIVE CONCENTRATION. PT = PERFORMANCE TEST, LABORATORY REAGENT WATER SPIKED WITH 1-100 $\mu \mathrm{G} / \mathrm{L}$ AS. ENV = ENVIRONMENTAL, SURFACE AND DRINKING WATERS WITH NATIVE AS RANGING FROM $<0.5$ TO $65 \mu \mathrm{G} / \mathrm{L}$ As.

\begin{tabular}{|c|c|c|c|}
\hline \multicolumn{4}{|l|}{ Quick Arsenic II } \\
\hline number of tests/kit & 50 & & \\
\hline product number & 481303 & & \\
\hline ITS website cost (kit / per test) [accessed March 21, 2018] & $\$ 229.99$ & $\$ 4.60$ & \\
\hline Amazon cost (kit / per test) [accessed March 21, 2018] & $\$ 294.81$ & $\$ 5.90$ & \\
\hline test graduations and range (website) [accessed March 21, 2018] & $\begin{array}{r}<1,2,3,4,5,6,7,8,10,13,20,25 \\
30,40,>50,>80,>120,>160 \mu \mathrm{g} / \mathrm{L}\end{array}$ & & \\
\hline test graduations and range (ETV) & $\begin{array}{r}2,2.5,3,3.5,4,5,6,7,10,12,14,20, \\
30,>30,>50,>70,>100,>150 \mu \mathrm{g} / \mathrm{L} \\
\end{array}$ & & \\
\hline optimal detection range (ETV) & $<10 \mu \mathrm{g} / \mathrm{L}$ & & \\
\hline recommended temperature range & $24-30 \mathrm{C}$ & & \\
\hline method detection level, (ETV) & $3.6-7.0 \mu \mathrm{g} / \mathrm{L}$ & & \\
\hline false positive rate & $0 \%$ & & \\
\hline technical operator & $0 \%$ & & \\
\hline non-technical operator & $0 \%$ & & \\
\hline false negative rate & $22 \%$ & & \\
\hline technical operator & $19 \%$ & & \\
\hline non-technical operator & $24 \%$ & & \\
\hline & range & average & st dev \\
\hline QCS percent recovery, operator average & $25 \%$ to $100 \%$ & $75 \%$ & $23 \%$ \\
\hline technical operator & $35 \%$ to $100 \%$ & $72 \%$ & $23 \%$ \\
\hline non-technical operator & $25 \%$ to $100 \%$ & $78 \%$ & $22 \%$ \\
\hline LFM percent recovery, operator average & $-3 \%$ to $100 \%$ & $56 \%$ & $27 \%$ \\
\hline technical operator & $50 \%$ to $100 \%$ & $66 \%$ & $19 \%$ \\
\hline non-technical operator & $-3 \%$ to $70 \%$ & $45 \%$ & $32 \%$ \\
\hline accuracy: relative bias, operator average, overall & $-77 \%$ to $96 \%$ & $-33 \%$ & $38 \%$ \\
\hline technical operator & $-61 \%$ to $10 \%$ & $-37 \%$ & $22 \%$ \\
\hline non-technical operator & $-77 \%$ to $96 \%$ & $-30 \%$ & $49 \%$ \\
\hline accuracy: relative bias, operator average, $P T$ waters & $-45 \%$ to $90 \%$ & $-8 \%$ & $38 \%$ \\
\hline technical operator & $-33 \%$ to $10 \%$ & $-18 \%$ & $18 \%$ \\
\hline non-technical operator & $-45 \%$ to $90 \%$ & $-1.1 \%$ & $48 \%$ \\
\hline accuracy: relative bias, operator average, ENV waters & $-77 \%$ to $-39 \%$ & $-56 \%$ & $12 \%$ \\
\hline technical operator & $-61 \%$ to $-50 \%$ & $-54 \%$ & $4 \%$ \\
\hline non-technical operator & $-77 \%$ to $-39 \%$ & $-58 \%$ & $16 \%$ \\
\hline accuracy: agreement $+/-1$ color block, operator average, overall & $70 \%$ & & \\
\hline technical operator & $68 \%$ & & \\
\hline non-technical operator & $72 \%$ & & \\
\hline accuracy: agreement $+/-1$ color block, operator average, $P T$ waters & $77 \%$ & & \\
\hline technical operator & $71 \%$ & & \\
\hline non-technical operator & $82 \%$ & & \\
\hline accuracy: agreement $+/-1$ color block, operator average, ENV waters & $64 \%$ & & \\
\hline technical operator & $64 \%$ & & \\
\hline non-technical operator & $64 \%$ & & \\
\hline
\end{tabular}


International Journal for Service Learning in Engineering,

Humanitarian Engineering and Social Entrepreneurship

Vol. 14, No. 1, pp. 32-46, Spring 2019

ISSN $1555-9033$

\section{TABLE 1B}

SUMMARY OF ENVIRONMENTAL TECHNOLOGY VERIFICATION (ETV) DATA FOR THE ITS QUiCK ARSENIC LOW-RANGE II TEST KIT (KAUFMAN ET AL. 2003B). QCS = QUALITY CONTROL STANDARD, LABORATORY REAGENT WATER SPIKED WITH $10 \mu \mathrm{G} / \mathrm{L}$ AS. LFM = LABORATORY FORTIFIED MATRIX, SAMPLES OF ENVIRONMENTAL WATER SPIKED WITH $10 \mu \mathrm{G} / \mathrm{L}$ AS ABOVE NATIVE CONCENTRATION. PT = PERFORMANCE TEST, LABORATORY REAGENT WATER SPIKED WITH 1-100 $\mu \mathrm{G} / \mathrm{L}$ AS. ENV = ENVIRONMENTAL, SURFACE AND DRINKING WATERS WITH NATIVE AS RANGING FROM $<0.5$ TO $65 \mu \mathrm{G} / \mathrm{L}$ AS.

\begin{tabular}{|c|c|c|c|}
\hline \multicolumn{4}{|l|}{ Quick Arsenic Low-Range II } \\
\hline number of tests/kit & 50 & & \\
\hline product number & 481301 & & \\
\hline ITS website cost (kit / per test) [accessed March 21, 2018] & $\$ 365.99$ & $\$ 7.32$ & \\
\hline Amazon cost (kit / per test) [accessed March 21, 2018] & $\$ 241.60$ & $\$ 4.83$ & \\
\hline test graduations and range (website) [accessed March 21, 2018] & $\begin{array}{r}<0.5,1.0,1.5,2.0,3.0,4,5,6,7,8 \\
12,>20,>30,>50 \mu \mathrm{g} / \mathrm{L}\end{array}$ & & \\
\hline test graduations and range (ETV) & $\begin{array}{r}0.6,1,1.3,1.7,2,2.5,3,4,5,7,9,10 \\
12,15,25,30,>30,>100 \mu \mathrm{g} / \mathrm{L} \\
\end{array}$ & & \\
\hline optimal detection range (ETV) & $<15 \mu \mathrm{g} / \mathrm{L}$ & & \\
\hline recommended temperature range & $24-30 \mathrm{C}$ & & \\
\hline method detection level, (ETV) & $1.2-1.5 \mu \mathrm{g} / \mathrm{L}$ & & \\
\hline false positive rate & $0 \%$ & & \\
\hline technical operator & $0 \%$ & & \\
\hline non-technical operator & $0 \%$ & & \\
\hline false negative rate & $48 \%$ & & \\
\hline technical operator & $62 \%$ & & \\
\hline non-technical operator & $33 \%$ & & \\
\hline & range & average & st dev \\
\hline QCS percent recovery, operator average & $25 \%$ to $100 \%$ & $57 \%$ & $18 \%$ \\
\hline technical operator & $25 \%$ to $100 \%$ & $54 \%$ & $20 \%$ \\
\hline non-technical operator & $40 \%$ to $100 \%$ & $60 \%$ & $16 \%$ \\
\hline LFM percent recovery, operator average & $15 \%$ to $100 \%$ & $48 \%$ & $36 \%$ \\
\hline technical operator & $15 \%$ to $60 \%$ & $43 \%$ & $17 \%$ \\
\hline non-technical operator & $25 \%$ to $100 \%$ & $53 \%$ & $51 \%$ \\
\hline accuracy: relative bias, operator average, overall & $-92 \%$ to $74 \%$ & $-33 \%$ & $38 \%$ \\
\hline technical operator & $-92 \%$ to $-8 \%$ & $-47 \%$ & $27 \%$ \\
\hline non-technical operator & $-74 \%$ to $74 \%$ & $-20 \%$ & $43 \%$ \\
\hline accuracy: relative bias, operator average, $P$ T waters & $-42 \%$ to $74 \%$ & $-12 \%$ & $36 \%$ \\
\hline technical operator & $-42 \%$ to $-8 \%$ & $-27 \%$ & $16 \%$ \\
\hline non-technical operator & $-4 \%$ to $74 \%$ & $2.4 \%$ & $46 \%$ \\
\hline accuracy: relative bias, operator average, ENV waters & $-92 \%$ to $-18 \%$ & $-58 \%$ & $22 \%$ \\
\hline technical operator & $-54 \%$ to $-92 \%$ & $-70 \%$ & $17 \%$ \\
\hline non-technical operator & $-74 \%$ to $-18 \%$ & $-45 \%$ & $20 \%$ \\
\hline accuracy: agreement $+/-1$ color block, operator average, overall & $42 \%$ & & \\
\hline technical operator & $45 \%$ & & \\
\hline non-technical operator & $38 \%$ & & \\
\hline accuracy: agreement $+/-1$ color block, operator average, $P T$ waters & $46 \%$ & & \\
\hline technical operator & $57 \%$ & & \\
\hline non-technical operator & $36 \%$ & & \\
\hline accuracy: agreement $+/-1$ color block, operator average, ENV waters & $36 \%$ & & \\
\hline technical operator & $32 \%$ & & \\
\hline non-technical operator & $40 \%$ & & \\
\hline
\end{tabular}

